\title{
Capital Adequacy and Risk Management in Insurance
}

\section{Henri de Castries}

GIE AXA, 25, ave. de Matignon, F-75008 Paris, France.

E-mail: Gaelle.Olivier@axa.com

This paper tells of the importance of capital for insurance companies and how, as a result of the crises of 2000-2003, they have learned to better manage their capital and risk.

The Geneva Papers (2005) 30, 47-51. doi:10.1057/palgrave.gpp.2510017

Keywords: capital adequacy; risk management; solvency

\section{Capital: The insurer's commodity}

What sets the insurance industry apart from all others is that it operates on an inverse cycle. That is, insurers receive payment before delivering the underlying service. In return for this special status, insurers reciprocate by reciting and keeping the expected promise: that they will be there, without fail, when the time comes to render the service to which they have committed, and that they will be in a position to fulfil their obligation. It is for this reason that - more than in any other industry - capital is one of the keys to the workings of the insurance business. It is capital that allows insurers to underwrite risks; it is capital that gives policyholders a window on the sustainability of the protection they have contracted; and it is capital that gives a hint to the employees about the financial shape of their employer.

For insurers, then, capital functions as a basic commodity that must be optimally exploited. And like all commodities, capital responds to the supply and demand dictates of the market. The experience of recent years offers a particularly telling illustration of this truth.

\section{0-2000: Capital is key - but the door is wide open}

For most of the major players in the insurance industry, the 1990s were a decade of substantial diversification, in both geographic and business terms.

The trend toward diversification was facilitated by a number of factors, namely, broader access to capital markets, the introduction of the euro, the development of new technologies, and the ease of information exchange that ensued. Diversification was also a response to the need expressed by clients for a broader range of protection options than was then being provided by the industry. Individuals wanted the traditional range of insurance products (property and casualty, life and savings) expanded to encompass longer-term protection options, including for instance financial and estate planning. Commercial clients wanted coverage expanded to include the new risks they were facing, such as those related to environmental impairment. 
Growth in the insurance industry near the end of the last century was largely facilitated - made possible, even - by relatively easy access to the capital markets that finance business expansion. Moreover, because supply was plentiful, the commodity known as capital was not expensive. In other words, "Capital is key... and the door is wide open".

However, this relatively easy access to capital also gave rise to certain perverse effects, including:

- myopia on the part of players as to the real financial return on their invested assets;

- decorrelation of the price of the service provided and the risk covered, due to an excessive focus on expected financial returns;

- non-optimization of capital adequacy requirements; and

- rudimentary approaches to risk and solvency needs.

Throughout, insurers experienced periods of wealth during which they were beset by the worries of the wealthy: the resources were there; it was up to them to grow their business by making the best possible use. Also, they had the triple benefit of high bond yields, high equity returns and over-capacity.

The major impact of this situation was the easing of underwriting terms and conditions: the price asked for the service rendered no longer reflected just the insured risk, it also reflected over-inflated return expectations on the assets received. In addition, as capital was in abundance, the need to optimize the commodity was not on anyone's agenda, and capital adequacy was assessed using rudimentary methods based on deterministic needs analyses.

Despite this somewhat severe judgement, we must not underestimate the power and agility of those players who wisely took advantage of the boom period to cultivate and seize on opportunities for growth.

On the other hand, while risk comes and goes relatively easily, grasping it and being able to come through on the coverage being proposed is a challenge that very few insurers were able to meet with success.

\section{0-2003: Capital is key - but the key is hard to find}

The situation changed radically as the 21 st century dawned, bringing with it plunging equity returns, low interest rates and a series of extremely sizeable claims (such as the World Trade Center).

Suddenly, capital had became a hot, sought-after commodity (200 billion dollars in equity was destroyed between 2000 and 2003) amid growing uncertainty on the part of investors as to what the future would bring (equity market volatility level is in that regard telling, with DJ/Eurostoxx average volatility of 28 per cent in 2001, compared with an average of 16 per cent in the 1990s). Like clients, investors got worried and hence raised the bar in terms of the guarantees they expected insurers to provide.

The consequences on the insurance industry were numerous:

- A return to business fundamentals, through more disciplined risk selection and better risk pricing. 
- A sharper focus on optimizing capital management through more sophisticated adequacy assessments and more efficient allocation. These two factors led to the issuance of 45 billion dollars in new equity between December 2002 and April 2004 either through the disposal of non-core businesses or fund-raising in the capital markets.

- Performance assessment based on return on invested capital, rather than on earnings alone.

For insurers, the up side was a return to business fundamentals and closer attention to the task of assessing risk and proposing adequate coverage.

\section{Risk more expensive for customers?}

For individual and commercial clients, the focus on risks became sharper. They began to demand higher levels of transparency with respect to the coverage and services they were purchasing, and they began to ask questions about prices in order to understand why protection had become more costly.

\section{Risk less rewarding for shareholders?}

Investors, in the meantime, became far more selective about where they were willing to put their money. They began to look more closely at the health of insurers before agreeing to support their development. The risk premium is only of any real value if it generates higher performance.

Insurers thus had to prove that they could differentiate themselves from other players, as well as demonstrate their agility under difficult circumstances. And to attract capital - the keystone to their development going forward - they had to show that any funding that flowed in their direction would be put to good use.

\section{4 onwards: Capital, a sophisticated key, expensive to replace - better not lose it}

Although a certain lull returned to the financial markets in 2004, they have not resumed to generating the excessive investment returns on display in the past.

As a result, capital remains under pressure from a number of sources:

- Regulators attach greater importance to the capital factor, a key indicator of insurance company solvency.

- Prevailing economic conditions, that is, low interest rates and sluggish equity markets, are pushing insurers to develop more ingenious products, notably in life insurance and retirement savings.

- Judicial inflation and major risks (such as the risk of terrorism or natural disaster) are still key factors in property and casualty insurance.

For insurers, the challenge is to refine capital adequacy modelling tools so that they better reflect the positive impact of their diversification - both geographic and global - as well as financial market uncertainties and risk scenarios. 
By improving their understanding of both the business and their needs, insurers will gain greater insight into the risk for which coverage is requested, and hence will be able to transform risk-taking into opportunity. In other words, they will return to the very core of their core business: managing risk. Risk is an opportunity and risk management is the key ring of capital.

\section{Capital management: A key opportunity for differentiation}

The difficult environment of recent years has therefore helped to clean up the insurance industry and shift the focus back to business fundamentals. An accurate assessment of their risks, combined with an accurate assessment of the capital required to meet their underwriting commitments is allowing insurers to continue operating in an environment that has raised the bar, both in terms of disclosure and profitability standards.

Those who have seized this opportunity now have the resources they need to move ahead of the pack by focusing on profitable growth, notably through product innovation in life and savings and through renewed underwriting capacity in property and casualty insurance, together with a reinforced focus on profitability.

Today, the insurance industry's development is deeply tied to how it uses the commodity called capital. And this can be evaluated by looking at three indicators:

- asset modelling based on a stochastic approach that factors in volatility;

- evaluation of industry players that takes into account both present value and the capacity to create value in the future; and

- estimates of profitability and capital adequacy that integrate the level of risk taken.

Greater sophistication in estimating capital adequacy requirements should lead to a better assessment of the diversification of players, in both business and geographic terms. However, its application does raise a few issues - issues whose examination by the industry is both healthy and timely:

- the consistency between the various approaches available for estimating capital adequacy requirements: regulatory, rating agencies, economic capital;

- the complexity of the methodology and, in particular, the importance of underlying hypotheses used for modelling (volatility, interest rates, risk scenarios, etc.);

- the comparability of estimates made by the various players;

- the assessment of property and casualty, banking and asset management businesses using this methodology, which today is more mature and more widely used for life and savings; and

- risk management.

Insurers face a genuine challenge, that of providing greater transparency with respect to their business and the risks they underwrite, and that of meeting a higher standard of disclosure in terms of their business and how they conduct it. 
By rising to this dual challenge, insurers will attract the resources they need to restore the high levels of development the industry experienced in the preceding century.

- This means becoming attractive to investors once again by providing better visibility on future performance and, in so doing, offering reassurances as to the industry's ability to deliver a future return on their investment.

- It also means developing solutions that address the needs expressed by their clients, in terms of products, transparency and, above all, quality of service.

\section{About the author}

Henri de Castries is Chairman of the Management Board and Chief Executive Officer of Axa and Chairman of AXA Financial, SA. 